\title{
Ionic Liquid-based Aqueous Two-phase System Coupled With Flame Atomic Absorption Spectrometry for the Preconcentration and Determination of Copper in Water Samples
}

\author{
Kamil Bostanci ${ }^{\mathrm{a}, \mathrm{b}}$ and Melek Merdivan*,c \\ a Dokuz Eylul University, Graduate School of Natural and Applied Science, \\ Tinaztepe Campus, 35860 Izmir, Turkey \\ ${ }^{b}$ Dokuz Eylul University, Torbalı Vocational School, 35860 Izmir, Turkey \\ ${ }^{c}$ Dokuz Eylul University, Chemistry Department, Tinaztepe Campus, 35160 Izmir, Turkey
}

\section{INTRODUCTION}

Many metals have been used in industrial, agricultural, technological, and scientific areas for years. However, there has been an increase in heavy metals accumulation in natural waters and soils which is of great concern since they are not biodegradable and accumulate in living organisms $(1,2)$.

Copper is one of the elements that plays an important role in many body functions, so monitoring at trace levels in real samples is important to assess possible environmental pollution. Copper at high amounts can become toxic and cause disturbances in the stomach and intestine resulting in nausea, vomiting, diarrhea and stomach cramps (3). It has also been reported that copper above $4 \mathrm{mg} / \mathrm{L}$ in drinking water can also lead to hemolysis or liver and kidney damage $(4,5)$.

Trace metal analysis generally requires separation and enrichment steps because of insufficient sensitivity of an instrumental technique, such as flame atomic absorption spectrometry. There are numerous extraction/preconcentration methods which includes solid phase extraction (SPE) (6), cloud point extraction (CPE) (7), single drop microextraction (8), and dispersive liquid-liquid microextraction

Corresponding autbor.

E-mail: melek.merdivan@deu.edu.tr Tel: +902323018693

\section{ABSTRACT}

An ionic liquid/aqueous twophase system (IL/ATPS) prior to flame atomic absorption spectrometry analysis was developed for the selective extraction of copper at trace levels in aqueous solution. The IL/ATPS was formed with ionic liquid consisting of three different cationic groups (phosphonium, ammonium, and imidazolium) having bromide as the anion group, Triton ${ }^{\circledR} \mathrm{X}-100$, and $\mathrm{K}_{2} \mathrm{HPO}_{4}$ in the presence of 8-hydroxyquinoline (8-HQ). The amount of ionic liquid, type and amount of salt, amount of 8-HQ, complexation of $\mathrm{pH}$, and amount of Triton $\mathrm{X}-100$ were optimized to achieve high extraction efficiency. Linearity for copper was in the range of 20-500 $\mu \mathrm{g} \mathrm{L}^{-1}$. The volume of the ionic liquid-rich upper phase varied from 250 to $700 \mu \mathrm{L}$. The limit of detection was 11,12 , and 17 $\mu \mathrm{g} \mathrm{L}^{-1}$ for MOIM-Br, TOA-Br, and TOP-Br, respectively. The developed method was successfully applied to tap water, well water, and seawater samples.

(DLLME) $(9,10)$ for the enrichment of trace metal ions. Recently, an aqueous two-phase system (ATPS) has been developed for metal separation/extraction, but it depends on using primarily water and nontoxic and non-flammable solvents (11). Aqueous two-phase systems are formed by mixing two water-soluble macromolecules or a water-soluble ionic liquid with some inorganic salts in a particular proportion. This system consists of two phases, one phase rich in ionic liquid or macromolecule including analyte, the other phase containing more inorganic salt $(12,13)$. Ionic liquids have excellent physicochemical properties and have been used to ensure that this separation technique is a safe and green process $(14,15)$. Advantages of ATPS over other methods such as SPE, DLLME, and CPE are environmentally friendly, easy to implement, low cost, recycling of components and fast phase separation $(16,17)$. Nitrogen-based ionic liquids containing imidazolium and pyrrolidinium cations have been widely used as an extractant in extraction/microextraction techniques (18-20). However, phosphoniumbased and ammonium-based ionic liquids have rarely been selected with extraction techniques, although they have similar or better thermal, chemical, and solvation properties (21-23).

In this study, the selective extraction of $\mathrm{Cu}(\mathrm{II})$ from aqueous media using an ionic liquid-based aqueous two-phase system (IL/ATPS) with different ionic liquids (tetraoctylphosphonium bromide, tetra-n-octylammonium bromide, 1-methyl-3-octylimidazolium bromide) and inorganic salt. Copper(II) was complexed with 8-hydroxyquinoline in the aqueous phase and Triton ${ }^{\circledR} \mathrm{X}-100$ as the surfactant which contributes to phase formation. The extraction of $\mathrm{Cu}$ (II) was optimized by examining the 
quantity of ionic liquid, the type and quantity of salt, the quantity of ligand, $\mathrm{pH}$ of complexation and quantity of surfactant, separately. The developed extraction method has successfully been applied to tap water, well water, and seawater samples.

\section{EXPERIMENTAL}

\section{Instrumentation}

The extraction experiments were performed using a Model Sonorex ultrasonic bath (Bandelin, Germany). Phase separation was performed with a Model NF200 centrifuge (Nuve, Turkey). A WTW pH 3110 model $\mathrm{pH}$ meter was used for $\mathrm{pH}$ measurements (WTW, Germany). The measurement of copper was determined using the Model PinAAcle ${ }^{\mathrm{TM}} 500$ flame atomic absorption spectrometer (PerkinElmer, Inc., Shelton, CT, USA). The instrumental parameters are given in Table I.

\section{Chemicals, Reagents, and Solutions}

Tetraoctylphosphonium bromide (TOP-Br), tetra-n-octylammonium bromide (TOA-Br), 1-methyl3-octylimidazolium bromide (MOIM-Br), 8-Hydroxyquinoline (8-HQ), ethyl alcohol, and spectroscopic grade $\mathrm{HCl}$ and $\mathrm{HNO}_{3}$ were purchased from Merck Millipore (Germany), Sigma Aldrich (St. Louis, MO, USA), and Tokyo Chemical Industry (Japan). Sodium dode-

TABLE I

FAAS Instrumental Operating Conditions

\begin{tabular}{lr}
\hline Element & $\mathrm{Cu}(\mathrm{II})$ \\
Instrument & PinAAcle 500 FAAS \\
Wavelength & $324.75 \mathrm{~nm}$ \\
HCL current & $30 \mathrm{~mA}(\mathrm{P} / \mathrm{N}$ \\
\multicolumn{2}{c}{$\mathrm{N} 305-0217, \mathrm{Lumina})$} \\
Air flow rate & $10 \mathrm{~L} / \mathrm{min}$ \\
$\mathrm{C}_{2} \mathrm{H}_{2}$ flow rate & $2.5 \mathrm{~L} / \mathrm{min}$ \\
Slit width & $0.7 \mathrm{~nm}$ \\
\hline
\end{tabular}

cyl sulfate, Triton X-100, potassium carbonate, disodium hydrogen phosphate, sodium phosphate, potassium dihydrogen phosphate, dipotassium hydrogen phosphate salts were supplied from Merck Millipore (Germany) and Sigma Aldrich (USA). High purity deionized water (resistivity $\geq 18 \mathrm{M} \Omega-\mathrm{cm}$ ) from a Milli-Q ${ }^{\mathrm{TM}}$ water purification system (Millipore Corporation, USA) was used throughout the experiments. All reagents were of analytical grade. The individual standard stock solution of copper (1000 $\mathrm{mg} \mathrm{L}^{-1}$ ) was purchased from Merck Millipore. The intermediate standard solution of $100 \mathrm{mg} \mathrm{L}^{-1}$ and the working solutions of copper (10, 1 , 0.5 to $0.2 \mathrm{mg} \mathrm{L}^{-1}$ ) were prepared by diluting with deionized water (up to 200 fold).

\section{Samples}

In this study, three types of water samples (tap water, well water, and seawater) were used. Tap water was supplied from the Chemistry Laboratory, Dokuz Eylul University, Izmir, Turkey. Well water was sampled from Urla districts of Turkey. Seawater was collected from the Aegean Sea (Urla coast), Izmir, Turkey. The water samples were filtered using a 0.45 um Millipore ${ }^{\circledR}$ cellulose membrane filter to remove suspended particulate matter. The samples were kept in a refrigerator at $4{ }^{\circ} \mathrm{C}$ until sample analysis.

\section{Procedure for Optimization}

A $5 \mathrm{~mL}$ amount of aqueous copper solution with a concentration of $1 \mu \mathrm{g} \mathrm{mL} \mathrm{m}^{-1}$ was placed into a 15 mL test tube, 0.1 to $1 \mathrm{~mL}$ of 0.01 mol L-1 8-HQ complexing agent added, and the $\mathrm{pH}$ varied from 3 to 9. After the complexation of $\mathrm{Cu}(\mathrm{II})$, 25 to $200 \mathrm{mg}$ of ionic liquid (TOP$\mathrm{Br}$, TOA-Br, and MOIM-Br), 50 to $250 \mathrm{mg}$ of Triton X-100, and 1-2.5 g of $\mathrm{K}_{2} \mathrm{HPO}_{4}$ were added, and the final mixture was diluted to $10 \mathrm{~mL}$ with deionized water. This mixture was ultrasonicated, centrifuged, and a green-colored ionic liquidrich upper phase was obtained. This analyte-rich phase ( 0.250 $1000 \mu \mathrm{L}$ ) was transferred to another tube by using a pipette, then diluted with $1 \mathrm{~mol} \mathrm{~L}^{-1}$ nitric acid, and the concentration of $\mathrm{Cu}$ (II) in this phase was determined by FAAS.

\section{IL/ATPS}

In the optimized aqueous twophase system, $5 \mathrm{~mL}$ of test solution (including copper at 20-500 $\mathrm{g} \mathrm{L}^{-1}$ ) or sample solution, $2 \mathrm{~mL}$ of $\mathrm{pH} 7$ buffer solution, and $0.5 \mathrm{~mL}$ of 0.01 mol L $\mathrm{L}^{-1}$ 8-HQ were added to a 15 $\mathrm{mL}$ test tube. Then, $75 \mathrm{mg}$ of ionic liquid, $100 \mathrm{mg}$ of Triton X-100 and $1 \mathrm{~g}$ of $\mathrm{K}_{2} \mathrm{HPO}_{4}$ were added, and the final volume of this solution was brought to $10 \mathrm{~mL}$ using deionized water. This mixture was agitated using an ultrasonic bath for 2 minutes and centrifuged for 3 minutes at $4000 \mathrm{rpm}$. Later, the obtained green-colored ionic liquid-rich upper phase $(250-700 \mu \mathrm{L})$ was transferred to another test tube. Finally, the ionic liquid-rich phase was diluted to $1 \mathrm{~mL}$ with $1 \mathrm{~mol} \mathrm{~L}^{-1}$ $\mathrm{HNO}_{3}$ and introduced to the FAAS for the determination of $\mathrm{Cu}$.

\section{RESULTS AND DISCUSSION}

\section{Optimization of IL/ATPS}

To achieve high extraction efficiency, the experimental parameters, such as $\mathrm{pH}$ of the system, amount of complexing agent, type and amount of inorganic salt, amount of ionic liquid, type and amount of surfactant, were optimized.

\section{Effect of $\mathrm{pH}$ and Concentration of 8-HQ}

A suitable $\mathrm{pH}$ of the system plays an important role in the efficient recovery of the metal ions. The effect of $\mathrm{pH}$ ranging from 3 to 9 was investigated in the aqueous test solution. The recovery of $\mathrm{Cu}$ (II) 
was between 40 to $60 \%$ at all studied $\mathrm{pH}$ values of the IL/ATPS system. It was found that the transfer of all $\mathrm{Cu}$ (II) ion to the ionic liquidrich phase was not achieved. It was concluded that the extraction of all $\mathrm{Cu}(\mathrm{II})$ was not carried out in the salt-rich phase. The extraction of free $\mathrm{Cu}$ (II) to ionic liquid-rich phase was not adequate. Best results were found when $\mathrm{Cu}(\mathrm{II})$ remained in the salt-rich phase rather than in the liquid-rich phase. Therefore, the complexation agent such as 8-HQ was added to investigate the extraction efficiency of $\mathrm{Cu}(\mathrm{II})$ into the ionic liquid-rich phase in the ATPS system. The complexation $\mathrm{pH}$ of $\mathrm{Cu}(\mathrm{II})-8-\mathrm{HQ}$ was studied in the range of 3 to 9. As seen in Figure 1, complexation caused an increase in the extraction yield of $\mathrm{Cu}(\mathrm{II})$ into ionic liquid-rich phase. For further experiments, $\mathrm{pH}$ 7 was selected. This $\mathrm{pH}$ value is in agreement with previous studies $(24,25)$.

The extraction efficiency of $\mathrm{Cu}$ (II) was tested by changing the concentration of 8-HQ from $1 \times 10^{-4}$ mol L ${ }^{-1}$ to $1 \times 10^{-3} \mathrm{~mol} \mathrm{~L}^{-1}$ in the IL-K $\mathrm{H}_{2} \mathrm{PO}_{4}$ two-phase system. As seen in Figure 2, the recovery percentage of $\mathrm{Cu}$ (II) was above $95 \%$ when the concentration of 8-HQ was $\geq 2 \times 10^{-4} \mathrm{~mol} \mathrm{~L}^{-1}$ in the extraction system. However, because of the possibility of other ions capable of complexing with $8-\mathrm{HQ}$ in real samples, for further studies the optimum complexing agent concentration of $5 \times 10^{-4} \mathrm{~mol} \mathrm{~L}^{-1}$ was chosen.

\section{Effect of Ionic Liquid Amount}

In this study, three ionic liquids of phosphonium, ammonium, and imidazolium as the cation group and bromide as the anion group (TOP-Br, TOA-Br and MOIM-Br) were used to optimize the IL/ATPS. Various amounts of ILs (25-200 $\mathrm{mg}$ ) were studied to investigate their extraction abilities and phase formation. As seen in Figure 3, the recoveries of all ILs studied were found above $90 \%$ with $75 \mathrm{mg}$ of IL. Above this amount, no remarkable increase was observed in the recovery. Also, to avoid a decrease in the enrichment factor, $75 \mathrm{mg}$ of IL was used for further experiments.

\section{Effect of Type and Amount} of Surfactant

The addition of surfactants contributes to the two-phase separation by micellization (26). One phase with a small volume is the surfactant-rich phase in which the analytes are extracted. The denser bulky aqueous phase, known as the surfactant-poor phase, has a small concentration of surfactant. Besides providing phase formation, surfactant addition directly affects the amount of ionic liquid and salt used in the aqueous two-phase system, and this effect decreases the amount of ionic liquid and salt required. Three different types of surfactants (sodium dodecyl sulfate as the anionic surfactant, cetyltrimethylammonium bromide as the cationic surfactant, Triton X-100 as the nonionic surfactant) were examined for their effect on phase separation. By using only Triton $\mathrm{X}-100$, the two-phase formation was achieved. Later, the effect of amount of Triton X-100 was investigated in the range of $20-250 \mathrm{mg}$ for three ILs studied (Figure 4). Phase formation was found above the addition of $50 \mathrm{mg}$ of Triton $\mathrm{X}-100$. The highest recovery of $\mathrm{Cu}(\mathrm{II})$ was obtained with $50 \mathrm{mg}$ of Triton X-100 for TOP-Br and TOA-Br and $100 \mathrm{mg}$ of Triton X-100 for MOIM-Br. The addition of surfactant also reduced the amount of salt added by $80 \%$ and caused fast phase separation.

\section{Effect of Salt}

Different kinds of salts (potassium carbonate, potassium sulfate, disodium hydrogen phosphate, trisodium phosphate, potassium dihydrogen phosphate, and dipotassium hydrogen phosphate) were

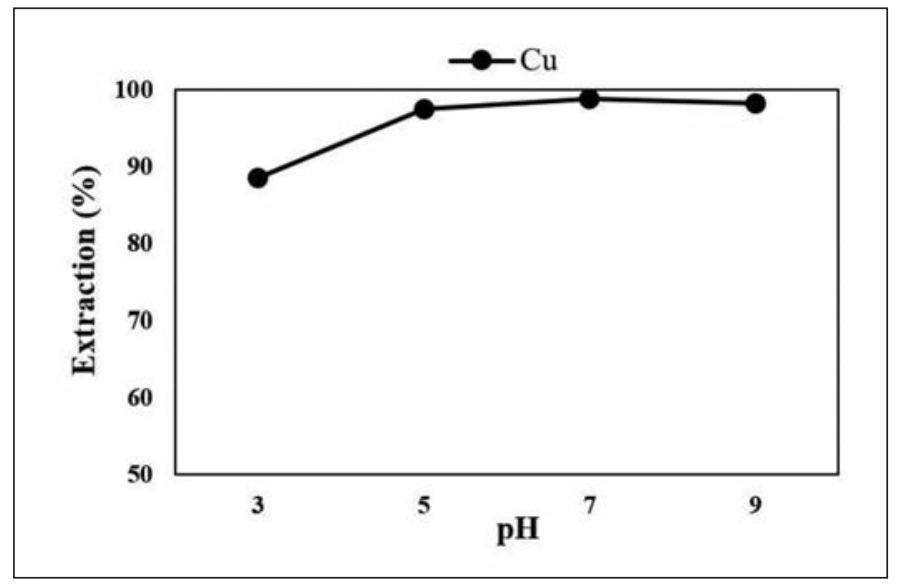

Fig. 1. Effect of $p H$ in the IL/ATP system.

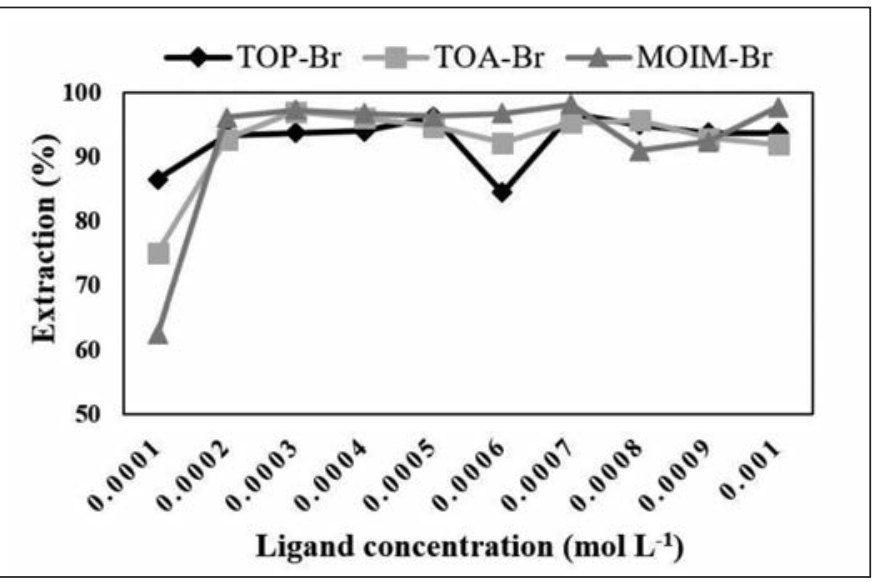

Fig. 2. Effect of concentration of 8-HQ in the IL/ATP system. 
examined for their effect in the formation and stability of the IL/ATP system. Two-phase formation was only seen by adding the appropriate amount of $\mathrm{K}_{2} \mathrm{HPO}_{4}$ to aqueous IL solution. Thus, it can be concluded that a high valence of $\mathrm{HPO}_{4}{ }^{2-}$ causes more hydration of water molecules and less hydration of IL. After determining the salt type, the amount of this salt was optimized by adding 1 to $2.5 \mathrm{~g}$ (Figure 5). In the ATP system, the amount of salt increases the hydrophobicity between the two phases, whereby the interaction between the ionic liquid and the metal increases. Taking into account the recovery and enrichment factor, the amount of $\mathrm{K}_{2} \mathrm{HPO}_{4}$ chosen was $1 \mathrm{~g}$ for TOP-Br, $1.5 \mathrm{~g}$ for TOA-Br, and $2 \mathrm{~g}$ for MOIM-Br.

\section{Effect of Other Metals}

The IL/ATPS system should be selectively used for the separation and enrichment of $\mathrm{Cu}$ (II) under optimized conditions in the presence of other metal ions. Some metal ions, such as $\mathrm{Ni}(\mathrm{II}), \mathrm{Co}(\mathrm{II})$, $\mathrm{Zn}$ (II), Cd(II), Fe(III), and Mn(II), are able to form complexation with 8-HQ (27). The effect of these ions was examined for $100 \mu \mathrm{g} \mathrm{L}^{-1} \mathrm{Cu}(\mathrm{II})$ by measuring the absorbance of Cu(II)-8-HQ complex before and after the addition of possible interfering ions. All of the cations studied were tolerated up to 10-fold of $100 \mu \mathrm{g} \mathrm{L}^{-1}$. For the possible interference of much higher concentrations of these metal ions, it is suggested to add a suitable masking agent in conjunction with the proposed IL/ATPS method.

\section{Analytical Performance of IL/ATPS}

Under optimized conditions, the analytical characteristics of the proposed IL/ATPS were evaluated, and the results are summarized in Table II. The linearity was in the range of 20 to $500 \mu \mathrm{g} \mathrm{L}^{-1}$ of $\mathrm{Cu}(\mathrm{II})$ for all IL studied, with a correlation coefficient higher than 0.998. The intraday and inter-day performance (relative standard deviation, RSD) of the proposed method at 100 $\mu \mathrm{g} \mathrm{L} \mathrm{L}^{-1} \mathrm{Cu}$ (II) for five replicates was between $1.20 \%$ and $4.86 \%$. The limit of detection (LOD), calculated as three times the standard deviation of the blank signals over the slope of the calibration curve, ranged from 11-17 $\mu \mathrm{g} \mathrm{L}^{-1}$ for all ILs studied. The volume of the upper phase was $250 \mu \mathrm{L}$ for MOIM-Br, $500 \mu \mathrm{L}$ for $\mathrm{TOP}-\mathrm{Br}$, and $700 \mu \mathrm{L}$ for TOA-BR based ATPS. The enrichment factor (defined as the concentration of $\mathrm{Cu}(\mathrm{II})$ in the upper phase over the initial concentration of $\mathrm{Cu}$ (II) in the sample solution) was increased from 47 to 104 in the order of TOA-Br $<$ TOP-Br $<$ MOIMBr based ATPS.

\section{Analysis of Real Samples \\ The proposed method was} applied to tap water, well water, and seawater for the extraction and determination of $\mathrm{Cu}(\mathrm{II})$ with TOP$\mathrm{Br}$ under optimized conditions. In the water samples, copper was not determined, which could be due to being below the detection limit. The accuracy of the method was verified by analysis of the samples spiked with 0.1 and $0.3 \mathrm{mg} \mathrm{L}^{-1}$ of $\mathrm{Cu}(\mathrm{II})$. The results given in Table III show that the proposed method provides good recoveries (80-104\%) and acceptable precision (1.25$5.76 \%)$. The reason for the low recovery of copper in the well and seawater samples could be explained with the possible high concentration of minerals competing for complexing of copper.

\section{CONCLUSION}

In the present study, an IL/ATPS method with ionic liquids, including the phosphonium, ammonium, and imidazolium cation group and bromide as the anion group, was developed and applied successfully

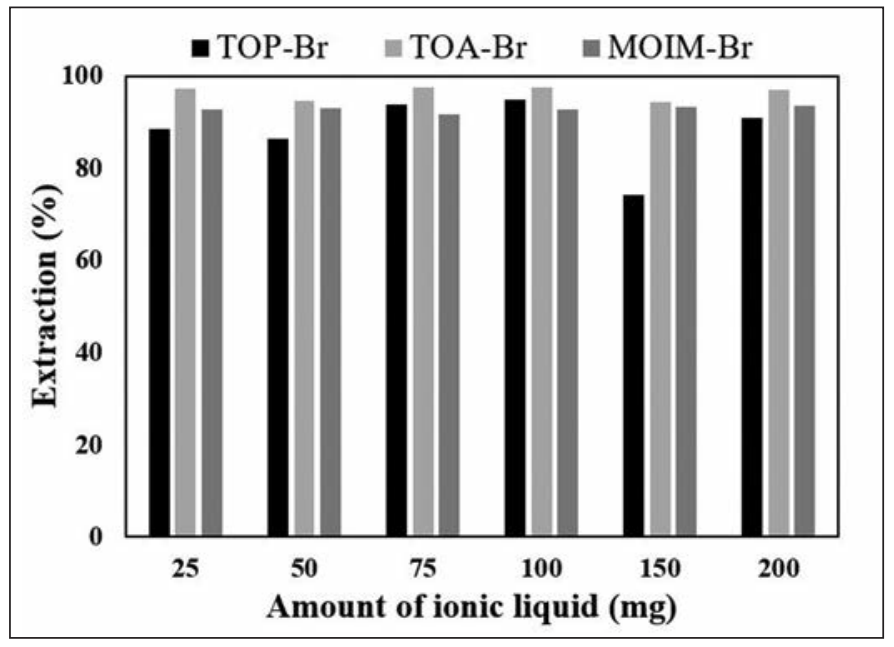

Fig. 3. Effect of ionic liquid amount in IL/ATP system.

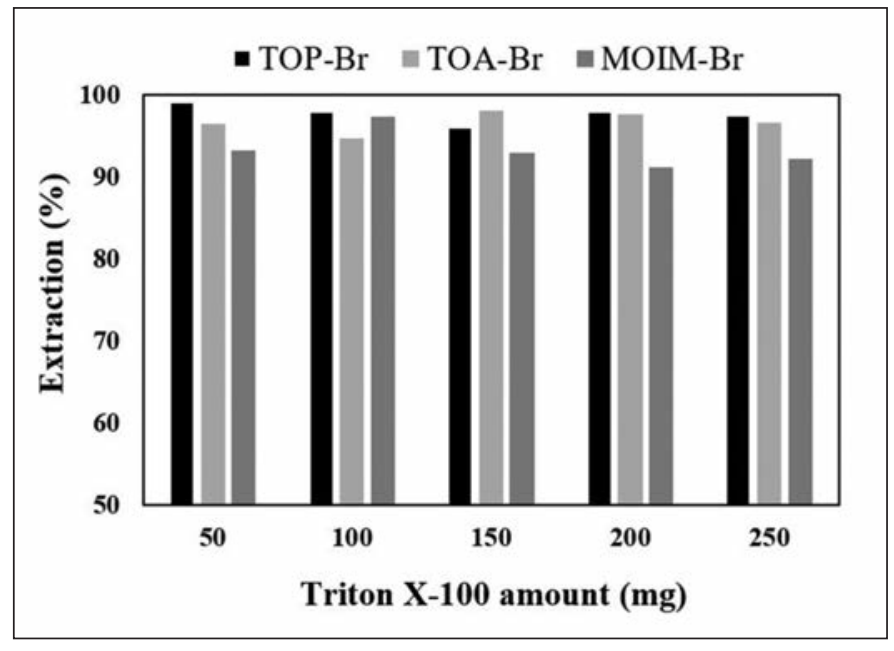

Fig. 4. Effect of Triton X-100 amount in IL/ATP system. 
to the analysis of water samples. Ionic liquids having phosphonium cation and imidazolium cation need less surfactant and salt. Also, better enrichment factors and fast phase separation were achieved by these ionic liquids. Metal ion was extracted into the ionic liquid-rich phase as metal complex using 8-HQ. All ionic liquids used in this method showed high extraction ability for copper in the aqueous system. Parameters affecting the extraction efficiency were optimized. This method is simple, fast, and environmentally friendly since there is no use of solvents. The IL/ATPS, especially with TOP-Br and MOIM-Br, provides a higher enrichment fac- tor and can be an alternative method for the determination of trace metal ions in environmental samples. It can also be stipulated that a much higher enrichment factor and a much lower detection limit of the proposed method could be achieved by increasing the sample volume.

\section{ACKNOWLEDGMENT}

This work was supported by Dokuz Eylul University Research Foundation (Project No: DEU 2015.KB.FEN.042).

Received December 7, 2018.

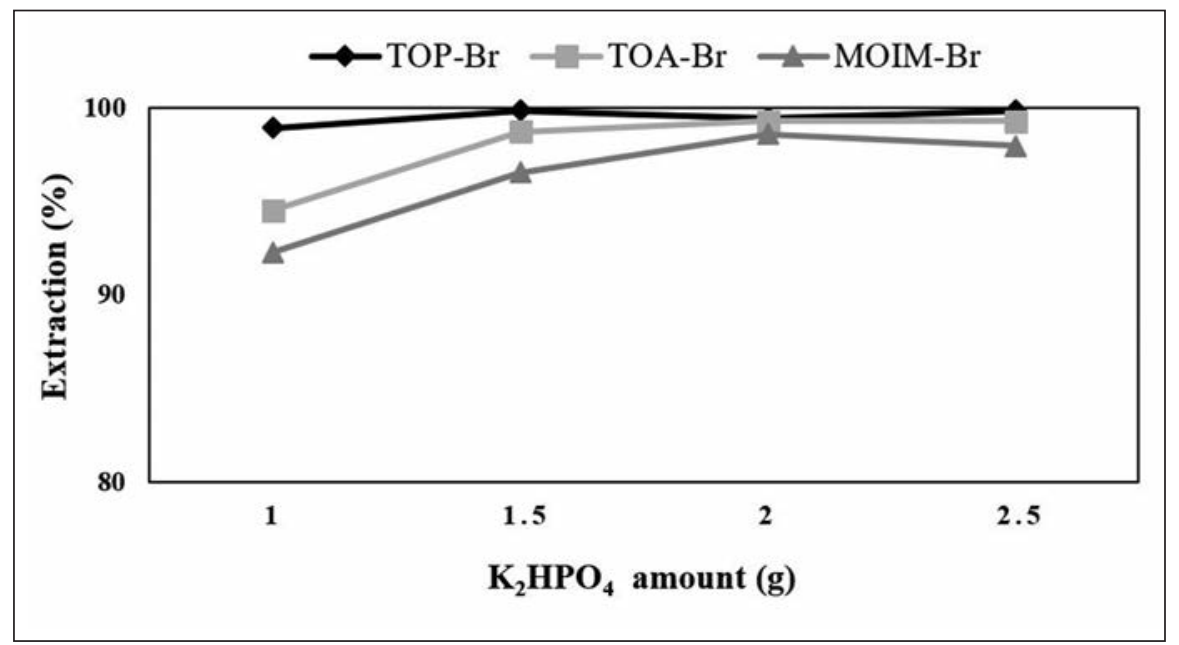

Fig. 5. Effect of salt amount in IL/ATP system.

TABLE II

Analytical Performance of $\mathrm{Cu}(\mathrm{II})$ in Aqueous Two-phase System

\begin{tabular}{llll}
\hline Ionic Liquid & TOP-Br & TOA-Br & MOIM-Br \\
\hline Correlation coefficient $(\mathrm{R})$ & 0.9996 & 0.9984 & 0.9994 \\
$\mathrm{~S}(\mathrm{y} / \mathrm{X})$ & $4.90 \times 10^{-4}$ & $9.80 \times 10^{-4}$ & $4.57 \mathrm{X} \mathrm{10}^{-4}$ \\
Linearity range $\left(\mu \mathrm{g} \mathrm{L}^{-1}\right)$ & $20-500$ & $20-500$ & $20-500$ \\
$\mathrm{LOD}\left(\mu \mathrm{g} \mathrm{L}^{-1}\right)$ & 17 & 12 & 11 \\
$\mathrm{LOQ}\left(\mu \mathrm{g} \mathrm{L}^{-1}\right)$ & 54 & 53 & 44 \\
$\% \mathrm{RSD}$, intra-day $\left(100 \mu \mathrm{g} \mathrm{L}^{-1}\right)$ & 2.14 & 2.04 & 2.25 \\
$\% \mathrm{RSD}$, inter-day $\left(100 \mu \mathrm{g} \mathrm{L}^{-1}\right)$ & 4.86 & 1.2 & 1.76 \\
Upper phase volume $\left(\mathrm{mL}^{2}\right)$ & 0.5 & 0.7 & 0.25 \\
Enrichment Factor $(\mathrm{EF})$ & 68 & 47 & 104 \\
\hline
\end{tabular}

\section{Atomic Apectroscopy \\ 1 Vol. 40(5), Sept./Oct. 2019}

\section{REFERENCES}

1. H. Wang, and Z.J. Ren, Water Res. 66, 219 (2014).

2. L.R. de Lemos, I.J.B. Santos, G.D. Rodrigues, L.H.M. da Silva, and M.C.H. da Silva, J. Hazard. Mater. 237, 209 (2012).

3. I. Durukan, C.A. Sahin, and S. Bektas, Microchem. J., 98, 215 (2011).

4. National Research Council, Dietary Reference Intakes for Vitamin A, Vitamin K, Arsenic, Boron, Chromium, Copper, Iodine, Iron, Manganese, Molybdenum, Nickel, Silicon, Vanadium and Zinc. National Academy Press, Washington, DC, USA, p. 224 (2001).

5. X. Jia, Y. Han, X. Liu, T. Duan and $\mathrm{H}$. Chen, Microchim. Acta 171, 49 (2010).

6. M. Soylak, Z. Erbas, At.. Spectrosc. 38, 57 (2017).

7. Y. Yamini, M. Faraji, S. Shariati, R. Hassani, and M. Ghambarian, Anal. Chim. Acta 612, 144 (2008).

8. X. Wen, Q. Deng, and J. Guo, Spectrochim. Acta A 79, 1941 (2011).

9. S. Yang, X. Fang, L. Duan, S. Yang, Z. Lei, and $\mathrm{X}$. Wen, Spectrochim. Acta A 148, 72 (2015).

10. Z.A. Alothman, M. Habila, E. Yilmaz, and M. Soylak, Atom. Spectrosc. 34, 175 (2013).

11. H. Cabezas, J. Chromatogr. B 680, 3 (1996).

12. K.P. Ananthapadmanabhan, and E.D. Goddard, Langmuir, 3, 25 (1987).

13. L.R. de Lemos, P.D. Patricio, G.D. Rodrigues, R.M.M. de Carvalho, M.C.H. da Silva, and L.H.M. da Silva, Fluid Phase Equilib. 305, 19 (2011).

14. M. Freemantle, Chem. Eng. News 76, 32 (1998).

15. G. Yin, S. Li, Q. Zhai, Y. Jiang, and $\mathrm{M}$. $\mathrm{Hu}$, Thermochimica Acta 566, 149 (2013).

16. S.V. Smirnova, T.O. Samarina, 
D.V. Ilin, and I.V. Pletnev, Anal. Chem. 90, 6323 (2018).

17. T. Yao, and S. Yao, J. Chromatogr. A 1481, 12 (2017).

18. C.F. Poole, and N. Lenca, Trends Anal. Chem. 71, 144 (2015).

19. C.F. Poole, and S.K. Poole, J. Chromatogr. A 1217, 2268 (2010).

20. J. An, M.J. Trujillo-Rodriguez, V. Pino, and J.L. Anderson, J. Chromatogr. A 1500, 1 (2017).

21. G.S. Medlina, and M. Reta, J. Sep. Sci. 39, 4209 (2016).

22. J.A. Lopez-Lopez, P. Pirkwieser, R. Leyma, W. Kandioller, R. Krachler, B.K. Keppler, F. Jirsa, and C. Moreno, J. Clean. Prod. 201, 22 (2018).

23. S.S. Foltova, T. Vander Hoogerstraete, D. Banerjee, and K. Binnemans, Sep. Purif. Technol. 210, 209 (2019).

24. C. Sgarlata, G. Arena, R.P. Bonomo, A. Giuffrida, and G. Tabbi, J. Inorg. Biochem. 180, 89 (2018).

25. M. Mameli, M.C. Aragoni, M. Arca, C. Caltagirone, F. Demartin, G. Farruggia, G. De Filippo, F.A. Devillanova, A. Garau, F. Isaia, V. Lippolis, S. Murgia, L. Prodi, A. Pintus, and A. Zaccheroni, Chem. Eur. J. 16, 919 (2010).

26. L. Liu, Y. liu, L. Du, Y. Zhao, and H. Du, Fluid Phase Equilibr. 415, 25 (2016).

27. L.L. Zhao, S.X. Zhong, K.M. Fang, Z.S. Qian, and J.R. Chen, J. Hazard. Mater. 239, 206 (2012). 